\title{
Determination of Cartilage Volume Using MRI in Patients with Knee Osteoarthritis: Efficacy Study of 25 Milligrams of Sodium Hyaluronate $(2.5 \mathrm{Ml})$ Versus Placebo
}

\author{
Weerachai Kosuwon*, Winai Sirichatiwapee, Tweechock Visanuyotin, Polasak Jeeravipoolvarn and Wiroon Laupattarakasem \\ Department of Orthopedics, Faculty of Medicine, Khon Kaen University, Khon Kaen, 40001, Thailand
}

\begin{abstract}
Background: Osteoarthritis $(\mathrm{OA})$ of the knee is prevalent and associated with both pain and functional disability. Visco-supplementation is an intra-articular therapeutic modality for the treatment of knee OA, based on the physiologic importance of hyaluronan in synovial joints. The therapeutic goal is to restore the viscoelasticity of synovial hyaluronan, decrease pain, improve mobility and restore the natural protective functions of hyaluronan in the joint radiography is currently the most widely used modality for assessing damage in OA: this technique allows the measurement of joint space width (JSW) the appropriate primary endpoint for demonstration of efficacy. There are, however, questions regarding its validity and reliability. Magnetic resonance imaging (MRI) with its superior soft tissue contrast is the best technique available for assessment of normal articular cartilage and cartilage volume. Therefore, this study aimed to evaluate the short-term benefit of intra-articular injection of hyaluronic acid $\left(\mathrm{GoOn}^{\circledR}\right)$ for protecting the articular by using MRI in patient with OA knee.
\end{abstract}

Patients and Methods: This was a phase III double-blinded (i.e., both the patients and MRI examiners), randomized, controlled trial of 60 patients with mild to moderate knee OA, diagnosed according to both clinical signs and X-ray. All of the patients received MRIs $(1.5 \mathrm{~T})$ of the affected knee(s) at visit 0 and 6 months after the first injection. The patients received either an intra-articular injection into the affected knee weekly for 5 weeks of HA $\left(\mathrm{GoOn}^{\circledR}\right)$ or a placebo. Blinded examiners used the visual analog scale (VAS) and the WOMAC score to do weekly and monthly assessments for 6 months. The engineer used Mimics 10.01 to transform the MRI scanner data into 3D images of the articular cartilage for measuring $\mathrm{CV}$, which was also blinded to the treatments.

Results: Subjects averaged 59.5 years of age (range, 46 to 84 ). During the enrollment phase, only female farmers attended came. Four patients in the placebo group and one in the $\mathrm{GoOn}^{\circledR}$ group refused to undergo the second MRI. The mean body weight and height was $64.20 \pm 10.25 \mathrm{~kg}$ and $1.53 \pm 0.057 \mathrm{~m}$, respectively. The respective baseline VAS and WOMAC score was $6.40 \pm 1.64$ and $51.65 \pm 13$.3. Forty-four patients were KL grade 2 and 16 were grade 3. The mean total $\mathrm{CV}$ at baseline in the $\mathrm{GoOn}^{\circledast}$ and placebo groups was $14.7 \pm 3.5 \mathrm{ml}$ and $15.5 \pm 3.9 \mathrm{ml}$, respectively. There was no significant difference in the mean total CV after 6 months in either group $(p>0.05)$ except at the femorotibial junction of the $\mathrm{GoOn}^{\circledast}$ group was increase $\mathrm{CV}$ more than the placebo group $(\mathrm{p}<0.05)$. The mean difference in the total WOMAC score and all three subscales in the $\mathrm{GoOn}^{\circledR} v s$. the placebo groups were statistically significant $(p<0.05)$. The difference in mean VAS between both groups was not statistically significant. No adverse events were reported.

Conclusion: $\mathrm{GoOn}^{\circledR}$ was an effective symptomatic treatment in mild to moderately painful OA knees according to the WOMAC score. In the short-term six-month period, there was not any change in the total cartilage volume except at the femoro-tibial junction.

Keywords: Osteoarthritis; knee; Cartilage volume; MRI; Hyaluronic acid

\section{Introduction}

Osteoarthritis (OA) is the most common form of arthritis in the population. A recent World Health Organization report on the global burden of disease indicated that knee OA is likely to become the fourth most important global cause of disability in women and the eighth in men [1]. Knee OA is associated with symptoms of pain and functional disability. The physical disability arising from pain and loss of functional capacity reduces the quality of life and increases the risk of further morbidity and mortality [2].

Hyaluronic acid (HA) - a polysaccharide consisting of nonsulphurated chains including dimmers of $\mathrm{N}$-acetylglucosamine and glycuronic acid is able to lubricate the joint with resultant protection of the articular cartilage; thereby (a) preventing mechanical injury to the cartilaginous tissue (b) absorbing the energy potentially injurious to, this tissue and (c) hydrating the connective tissue [3]. There have consequently been many studies on the benefit of HA in OA knee [4-9].

Radiography is currently the most widely used method for assessing damage in $\mathrm{OA}$; however, this technique is unable to quantify the cartilage volume of the joint. Magnetic resonance imaging (MRI) with its superior soft tissue contrast is the best technique available for assessing normal articular cartilage, its volume and progression rates of cartilage damage in osteoarthritic knee [10-13]. There has not, however, been any study of HA using MRI change in a cartilage volume in OA. This study was, therefore, proposed to assess by MRI the change

*Corresponding author: Weerachai Kosuwon, Department of Orthopedics, Faculty of Medicine, Khon Kaen University, Khon Kaen, 40001, Thailand, E-mail Weera_ko@kku.ac.th

Received April 27, 2012; Accepted June 25, 2012; Published June 26, 2012

Citation: Kosuwon W, Sirichatiwapee W, Visanuyotin T, Jeeravipoolvarn $P$ Laupattarakasem W (2012) Determination of Cartilage Volume Using MRI in Patients with Knee Osteoarthritis: Efficacy Study of 25 Milligrams of Sodium Hyaluronate (2.5 Ml) Versus Placebo. Clin Exp Pharmacol 2:112. doi:10.4172/2161. 1459.1000112

Copyright: (c) 2012 Kosuwon W, et al. This is an open-access article distributed under the terms of the Creative Commons Attribution License, which permits unrestricted use, distribution, and reproduction in any medium, provided the original author and source are credited. 
in cartilage volume between an intra-articular injection of $25 \mathrm{mg}$ of sodium hyaluronate $(2.5 \mathrm{ml})\left(\mathrm{GoOn}^{\circ}\right)$ and a placebo

\section{Patients and Methods}

\section{Methods}

This was a phase III double-blinded (i.e., both the patients and MRI examiners), randomized, controlled trial of 60 patients with mild to moderate knee OA, diagnosed by both clinical signs and X-ray. All of the patients received MRIs $(1.5 \mathrm{~T})$ of the affected knee(s) at visit 0 and 6 months after the first injection. The patients received either a weekly (for five weeks) intra-articular injection of $25 \mathrm{mg}$ of sodium hyaluronate $(2.5 \mathrm{ml})\left(\mathrm{GoOn}^{\circ}\right)$ into the affected knee or a placebo (normal saline). Blinded examiners used the visual analog scale (VAS) and the WOMAC score to do weekly and monthly assessments for 6 months.

\section{Inclusion criteria} criteria:

Subjects eligible for enrollment in the study met all of the following

1. Be capable of giving written informed consent;

2. Ambulatory females (non-pregnant) and males between 40 and under 80 years of age;

3. Be off any pain medication or nutritional supplements for symptomatic relief of knee $O A$ at least 15 days before screening;

4. Have pain at or below $80 \mathrm{~mm}$ on a $100 \mathrm{~mm}$ VAS in the index knee;

5. Have a documented diagnosis of knee OA, or meet the American College of Rheumatology (ACR) clinical criteria for classification of idiopathic (primary) OA at least 6 months prior to screening. If $\mathrm{OA}$ presents in both knees, the investigator will identify which knee will be X-rayed for study entry, with preference given to the knee with more severe pain $(\leq 80 \mathrm{~mm}$ VAS);

6. Have documented radiographic evidence of OA of the knee from the screening visit radiograph, of grade 2 or 3 according to the Kellgren and Lawrence Radiographic Grading [14];

7. Have a minimum baseline joint space in the medial and lateral compartments of the index knee of $\geq 1.5$ and $\geq 2.5 \mathrm{~mm}$, respectively, measured from radiographs in the MTP view; and,

8. Be able to understand and complete pain/function, global arthritis evaluation, and health outcome assessments.

\section{Exclusion criteria}

Subjects with any of the following criteria were not enrolled:

1. Having any skin lesion at the index knee;

2. A history of lower extremity surgery or injury/disease to the index knee within 6 or 12 months, respectively; and,

3. Under treatment with medications that might affect bone or cartilage metabolism, such as:

- chronic systematic corticosteroids;

- hyaluronan injection into the index knee within the previous 6 months; or,

- diacerin or glucosamine treatment within the last 12 months.
Subjects were assigned to the study treatment using a randomization schedule stratified by KL grade (grade 2 or 3 ). At the baseline/ randomization visit, each subject was randomly assigned to either the sodium hyaluronate or placebo saline treatment. Sodium hyaluronate or saline were injected five times intra-articularly into the knee joint.

The patient underwent MRI with a 1.5 Tesla using a phased array knee coil. A positioning device was used to ensure uniform placement of the knee among subjects. T2-weighted fat-suppressed images in the sagittal and coronal planes were taken, using the following pulse sequence parameters: repetition time (TR) $3610 \mathrm{~ms}$, echo time (TE) 40 ms, slice thickness $3.5 \mathrm{~mm}$ and field of view (FOV) $14 \mathrm{~cm}$. T1-weighted spin images in the sagittal plane were acquired, using the following pulse sequence parameters: TR $480 \mathrm{~ms}$, TE $24 \mathrm{~ms}$, slice thickness 3.5 $\mathrm{mm}$ and FOV $14 \mathrm{~cm}$.

The MRI engineer used the Mimics 10.01 image processing software for 3-D design and modeling, commercially developed by Materialise NV to transform the MRI scanner data into 3D images of the articular cartilage and measure the cartilage volume (CV) (Figure 1). This technique of measuring the $\mathrm{CV}$ in our institute was reliable; the respective intraclass correlation coefficient $(r)$ between assessors and by each assessor was 0.76 and 0.89 , respectively $(\mathrm{N}=15)$. The BlandAltman analysis of 15 knees also showed a marked decrease in the mean difference between the two observers and a narrowing of the $95 \%$ confident interval. The mean difference was $-0.19 \mathrm{ml}(95 \% \mathrm{CI}-0.36$ to $0.08)$.

The primary endpoint was the change from the MRI CV at baseline and after 6 months of the injections. The secondary endpoints were the VAS and WOMAC scores. A written diary was kept by each subject for recording the medications used to alleviate the pain associated with OA.

The study drug used was blinded to the subjects and the MRI interpreter. The research nurse prepared the treatment and placebo syringes.

\section{Sample size determination}

Based on our pilot study of fifteen old-age persons, the estimated mean cartilage volume of the knee joint was $16 \pm 3 \mathrm{ml}$. An estimated mean difference of GoOn and placebo was $15 \%$, at $\alpha$ of 0.05 (twosided) and a $\beta$ of 0.2 . The estimated sample size was, therefore, 26 cases per group.

\section{Statistical methods}

The mean difference in the $\mathrm{CV}$ between the GoOn and placebo groups was compared using a T-test. The confidence interval of the mean of the CV in each treatment group was also calculated. Other baseline factors such as WOMAC, stiffness score and acetaminophen use were analyzed using ANOVA and a student $\mathrm{T}$ test performed where appropriate.

All statistical analyses were performed using STATA Statistical Software: Release 10. (StataCorp. 2007. Stata Statistical Software: Release 10. College Station, TX:StataCorp.)

The Khon Kaen University Ethics Committee for Human Research approved the study in accordance with the Helsinki Declaration. All of the subjects gave informed consent. The registration number for the research is Clinical trials. Gov. IDNCT00750724.

\section{Results}

Age averaged 59.5 years (range, 46 to 84 ). During the enrollment 
Citation: Kosuwon W, Sirichatiwapee W, Visanuyotin T, Jeeravipoolvarn P, Laupattarakasem W (2012) Determination of Cartilage Volume Using MRI in Patients with Knee Osteoarthritis: Efficacy Study of 25 Milligrams of Sodium Hyaluronate (2.5 MI) Versus Placebo. Clin Exp Pharmacol 2:112. doi:10.4172/2161-1459.1000112
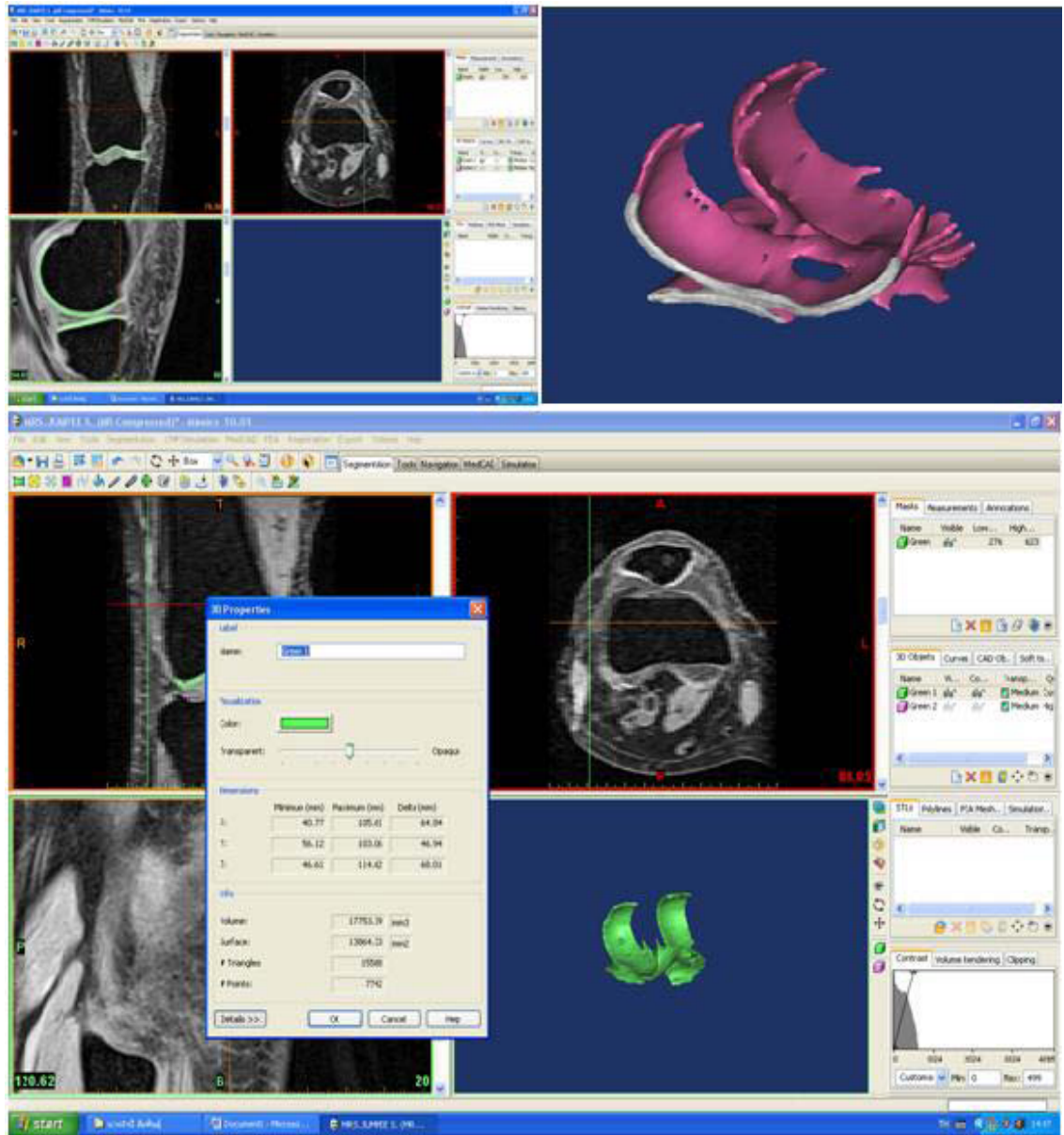

Figure 1: The Program Mimic 10.01 transforms the MRI data to a 3D image of the articular cartilage then calculates the volume.

phase, only female farmers came. There were 4 patients in the placebo group and 1 in the GoOn group who refused to undergo the second MRI.

The respective mean body weight and height was $64.20 \pm 10.25$ $\mathrm{kg}$ and $1.53 \pm 0.057 \mathrm{~m}$ respectively. The respective baseline VAS and WOMAC score was $6.40 \pm 1.64$ and $51.65 \pm 13.3$. According to the KL criteria, the severity of OA was: 44 patients with grade 2 and 16 with grade 3 (Table 1).

The respective mean total $\mathrm{CV}$ at baseline of the GoOn and the placebo groups was $14.7 \pm 3.5 \mathrm{ml}$. and $15.5 \pm 3.9 \mathrm{ml}$. The respective mean total CV after 6 months in the GoOn and the Placebo groups was 17.2 $\pm 3.5 \mathrm{ml}$ and $15.7 \pm 2.2 \mathrm{ml}$. The respective mean difference of $\mathrm{CV}$ from baseline in the GoOn' and Placebo groups was increased $2.4 \pm 4.9 \mathrm{ml}$ and $0.1 \pm 4.3 \mathrm{ml}$; however, the difference was not statistically significant $(\mathrm{p}>0.05)$. Neither was the respective difference statistically significant between the mean $\mathrm{CV}$ at various sites (distal femur, proximal tibia and patella) except at the femoro-tibial junction of the GoOn group was increase CV more than the placebo group $(\mathrm{p}<0.05)$ (Table 2).

The difference in VAS means between groups was not significant (Figure 2); the mean difference in the total WOMAC score and all three subscales indicated significantly more improvement in the GoOn group than the placebo group $(\mathrm{p}<0.05)$ (Figure 3$)$. No adverse events were reported.

\section{Discussion}

This was the first randomized controlled study to determine the efficacy of hyaluronic acid and the change in the CV of the knee joint using MRI as well as the first in using Mimics version 10.01 for the transformation of MRI data for measuring cartilage volume. The mean of the total CV of the knee joints measured with this technique ranged between 14.97 and $15.28 \mathrm{ml}$, which is similar to the volume found using other techniques [15-18]; suggesting that this method is as reliable as other measurement methods [17]. The validity of this technique was not, however, feasibly achieved in this study.

We had only females in the study so the results cannot be extrapolated to males. Most of the women were still working (despite reaching retirement age), which represents the real situation of village women in Thailand, who continue working on the farm, resulting in further cartilage destruction.

Although the predominant mechanism of intra-articular hyaluronic acid (HA) for the treatment of pain associated with knee osteoarthritis (OA) is unknown; in vivo, in vitro and clinical studies have demonstrated various physiological effects of exogenous HA. HA can reduce the nerve impulses and sensitivity associated with the pain of OA. Exogenous HA enhances chondrocyte HA and proteoglycan synthesis, reducing the production and activity of proinflammatory mediators and matrix metalloproteinase, and altering the behavior of immune cells. Many of the physiological effects of exogenous HA 
Citation: Kosuwon W, Sirichatiwapee W, Visanuyotin T, Jeeravipoolvarn P, Laupattarakasem W (2012) Determination of Cartilage Volume Using MRI in Patients with Knee Osteoarthritis: Efficacy Study of 25 Milligrams of Sodium Hyaluronate (2.5 MI) Versus Placebo. Clin Exp Pharmacol 2:112. doi:10.4172/2161-1459.1000112

may be a function of its molecular weight $[4,5]$. Several physiological effects probably contribute to the mechanisms by which HA exert their clinical effects in knee OA [4-7]. GoOn is a bacterial fermentation product and has a molecular weight of $1.4 \times 10^{6}$ Dalton. It is believed that this molecular weight is both visco-supplemental to, and viscoinductive of, hyaluronic acid [4-5].

In this study, only the WOMAC scores were significantly improved in the GoOn over against the placebo; the VAS scores were not different. These symptomatic results were similar as other study [7-9]. The placebo effect size in OA trial tends to be large compared to the untreated baseline especially in those involving intra-articular injection. Moreover, there is theoretical possibility that intra-articular saline could have therapeutic effect to that may be sustained for 6 months or more. Also, a therapeutic effect of aspiration of synovial fluid may contribute to a response in patients receiving placebo [19]. The annual rates of articular cartilage volume reduction ranged between $-1.5 \%$ and $0.0 \%$ [18]; therefore, this short-term, 6-month follow-up showed no

\begin{tabular}{|c|c|c|}
\hline & $\begin{array}{l}\text { GoOn }^{\circledast} \text { group } \\
\mathrm{N}=30\end{array}$ & $\begin{array}{l}\text { Placebo group } \\
\mathrm{N}=30\end{array}$ \\
\hline Females:males & $30: 0$ & $30: 0$ \\
\hline Age & $61.1 \pm 7.56$ & $61.2 \pm 7.30$ \\
\hline Weight (kg) & $63.7 \pm 9.85$ & $65.3 \pm 9.48$ \\
\hline Height (m) & $1.53 \pm 0.04$ & $1.54 \pm 0.06$ \\
\hline BMI & $27 \pm 0.2$ & $26 \pm 0.4$ \\
\hline X-ray KL2:3 & $23: 7$ & $21: 9$ \\
\hline Rt:Lt & $13: 17$ & $15: 15$ \\
\hline VAS & $6 \pm 2$ & $7 \pm 1.38$ \\
\hline WOMAC & $40 \pm 11$ & $43 \pm 13.37$ \\
\hline Cartilage Volume $(\mathrm{ml})$ & $14.7 \pm 3.5$ & $15.5 \pm 3.9$ \\
\hline
\end{tabular}

Table 1: Baseline clinical data.

\begin{tabular}{|c|c|c|c|c|c|}
\hline & Total volume & $\begin{array}{c}\text { Femoral } \\
\text { volume }\end{array}$ & $\begin{array}{c}\text { Tibial } \\
\text { volume }\end{array}$ & $\begin{array}{c}\text { Femoro-tibial } \\
\text { contact area } \\
\text { volume* }\end{array}$ & Patella \\
\hline $\begin{array}{c}\text { Baseline } \\
\text { Placebo } \\
\text { GoOn }\end{array}$ & $15.5 \pm 3.9$ & $7.4 \pm 1.2$ & $3.4 \pm 0.7$ & $10.9 \pm 1.7$ & $0.9 \pm 0.2$ \\
\hline $\begin{array}{c}\text { 6-month } \\
\text { Placebo }\end{array}$ & $15.7 \pm 3.5$ & $8.0 \pm 1.5$ & $3.4 \pm 0.7$ & $11.4 \pm 2.0$ & $1.0 \pm 0.2$ \\
\hline GoOn $^{\circledR}$ & $17.2 \pm 3.5$ & $9.5 \pm 1.2$ & $4.3 \pm 0.7$ & $12.9 \pm 1.8$ & $1.3 \pm 0.2$ \\
\hline
\end{tabular}

*significant difference $\mathrm{p}<0.05$

Table 2: The Mean and Standard deviation of cartilage volumes $(\mathrm{ml})$ at baseline and 6 months.

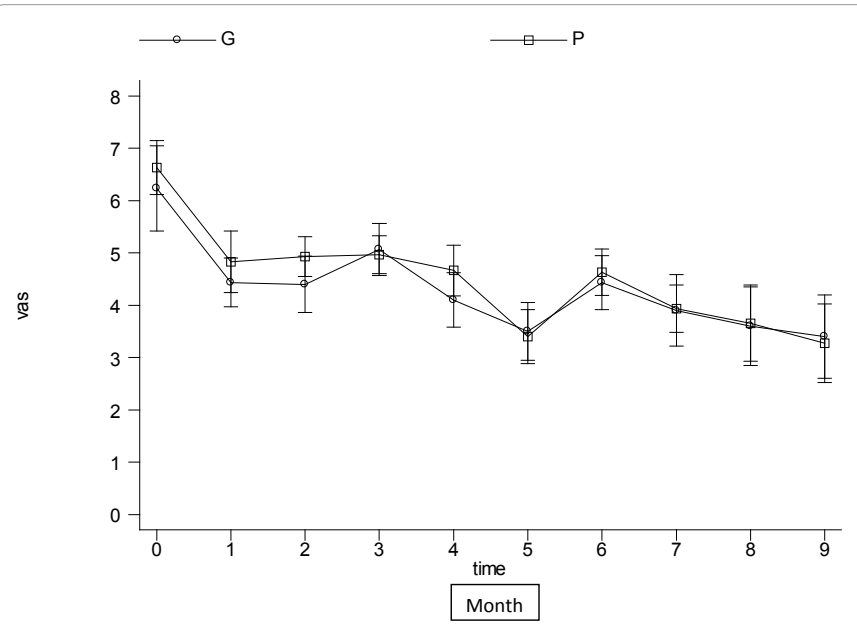

Figure 2: The VASs of patients in the $\mathrm{GoOn}^{\circledR}(\mathrm{G})$ and Placebo $(P)$ groups were not significantly different.

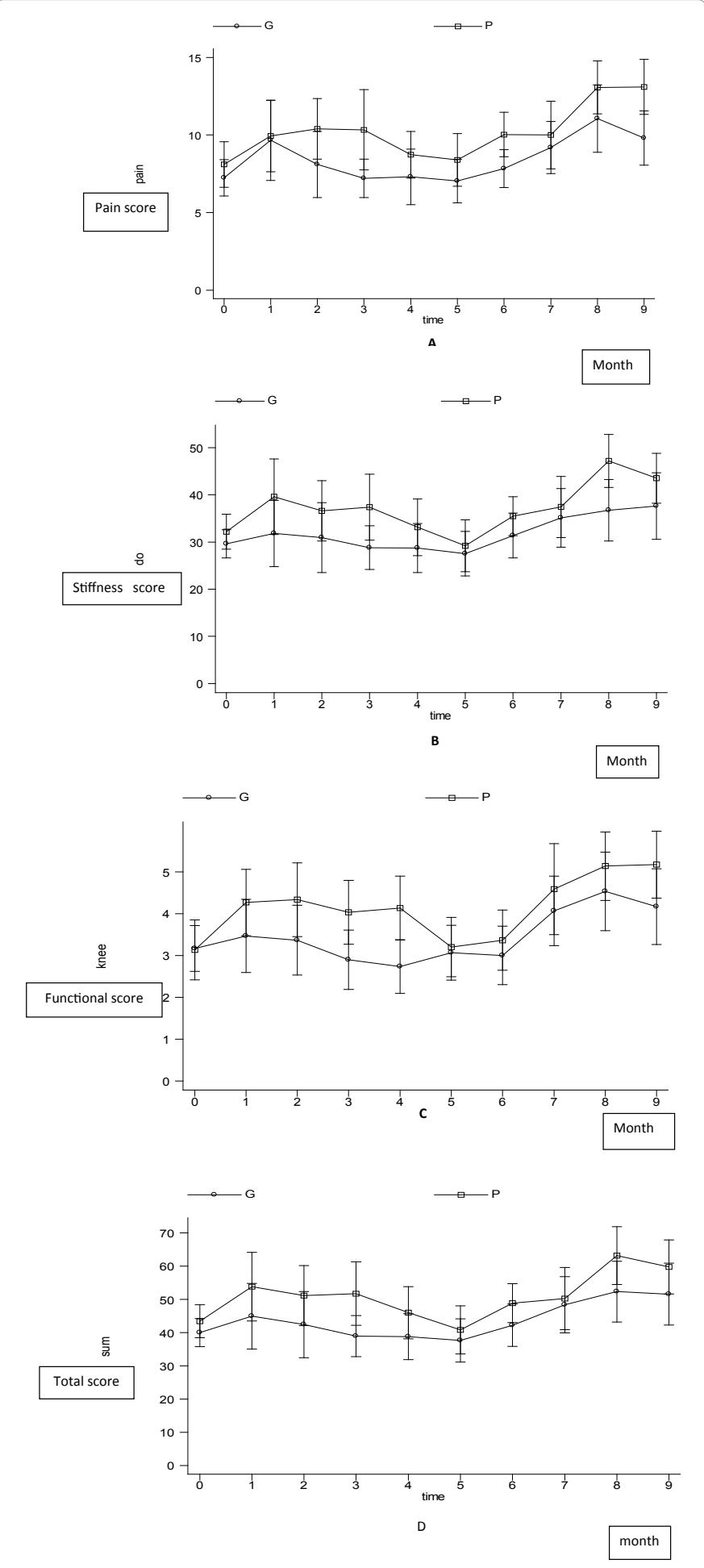

Figure 3: WOMAC scores; pain subscale $(A)$, stiffness subscale $(B)$, functional subscale $(C)$, and total score $(D)$ were all significantly different between the $\mathrm{GoOn}^{\circledR}(\mathrm{G})$ and Placebo $(P)$ groups $(p<0.05)$.

difference in cartilage volume between groups. Moreover, the sample size was insufficient to detect the true difference in $\mathrm{CV}$.

\section{Conclusion}

$\mathrm{GoOn}^{\circ}$ was an effective symptomatic treatment in mild to 
Citation: Kosuwon W, Sirichatiwapee W, Visanuyotin T, Jeeravipoolvarn P, Laupattarakasem W (2012) Determination of Cartilage Volume Using MRI in Patients with Knee Osteoarthritis: Efficacy Study of 25 Milligrams of Sodium Hyaluronate (2.5 MI) Versus Placebo. Clin Exp Pharmacol 2:112. doi:10.4172/2161-1459.1000112

moderately painful OA knees according to WOMAC scores; however, there was no change in the cartilage volume in the short-term (6-month period).

\section{Acknowledgements}

The authors thank (a) the patients for their participation, (b) the Department of Orthopedics and the Faculty of Medicine, for their support and (c) Mr. Bryan Roderick Hamman and Mrs. Janice Loewen-Hamman for their assistance with the English-language presentation of the manuscript.

\section{References}

1. Murray CJL, Lopez AD (1997) The global burden of disease. Geneva:World Health Organisation.

2. Guccione AA, Felson DT, Anderson JJ, Anthony JM, Zhang Y, et al. (1994) The effects of specific medical conditions on the functional limitations of elders in the Framingham Study. Am J Public Health 84: 351-358.

3. Peat G, McCarney R, Croft P (2001) Knee pain and osteoarthritis in older adults: a review of community burden and current use of primary health care. Ann Rheum Dis 60: 91-97.

4. Abatangelo G, O Regan M (1995) Hyaluronan: biological role and function in articular joint. Eur J Rheumatol Inflam 15:9-16.

5. Creamer P, Sharif M, George E, Meadows K, Cushnaghan J, et al. (1994) Intra-articular hyaluronic acid in osteoarthritis of the knee: an investigation into mechanisms of action. Osteoarthritis Cartilage 2: 133-140.

6. Frizziero L, Govoni E, Bacchini P (1998) Intra-articular hyaluronic acid in the treatment of osteoarthritis of the knee: clinical and morphological study. Clin Exp Rheumatol 16: 441-449.

7. Huskisson EC, Donnelly S (1999) Hyaluronic acid in the treatment of osteoarthritis of the knee. Rheumatology (Oxford) 38: 602-607.

8. Wang CT, Lin J, Chang CJ, Lin YT, Hou SM (2004) Therapeutic effects of hyaluronic acid on osteoarthritis of the knee. A meta-analysis of randomized controlled trials. J Bone Joint Surg Am 86A: 538-45.

9. Lo GH, LaValley M, McAlindon T, Felson DT (2003) Intra-articular hyaluronic acid in treatment of knee osteoarthritis: a meta-analysis. JAMA 290: 3115-3121.
10. Wluka AE, Wolfe R, Stuckey S, Cicuttini FM (2004) How does tibial cartilage volume relate to symptoms in subjects with knee osteoarthritis? Ann Rheum Dis 63: 264-268.

11. Kornaat PR, Bloem JL, Ceulemans RY, Riyazi N, Rosendaal FR, et al. (2006) Osteoarthritis of the knee: association between clinical features and MR imaging findings. Radiology 239: 811-817.

12. Hunter DJ, March L, Sambrook PN (2003) The association of cartilage volume with knee pain. Osteoarthritis Cartilage 11: 725-729.

13. Cibere J, Sayre EC, Guermari A, Nicolaou S, Kopec JA, et al. (2011) Natura history of cartilage damage and osteoarthritis progression on magnetic resonance imaging in a population-based cohort with knee pain. OsteoArthritis and Cartilage 19: 683-688.

14. KELLGREN JH, LAWRENCE JS (1957) Radiological assessment of osteoarthrosis. Ann Rheum Dis 16: 494-502.

15. Abadie E, Ethgen D, Avouac B, Bouvenot G, Branco J, et al. (2004) Recommendations for the use of new methods to assess the efficacy of disease-modifying drugs in the treatment of osteoarthritis. Osteoarthritis Cartilage 12: 263-268.

16. Eckstein F, Schnier M, Haubner M, Priebsch J, Glaser C, et al. (1998) Accuracy of cartilage volume and thickness measurements with magnetic resonance imaging. Clin Orthop Relat Res 352: 137-148.

17. Burgkart R, Glaser C, Hyhlik-Dürr A, Englmeier KH, Reiser M, et al. (2001) Magnetic resonance imaging-based assessment of cartilage loss in severe osteoarthritis: accuracy, precision, and diagnostic value. Arthritis Rheum 44: 2072-2077.

18. Bruyere O, Genant H, Kothari M, Zaim S, White D, et al. (2007) Longitudina study of magnetic resonance imaging and standard X-rays to assess disease progression in osteoarthritis. Osteoarthritis Cartilage 15: 98-103.

19. Bannuru RR, Natov NS, Dasi UR, Schmid CH, McAlindon TE (2011) Therapeutic trajectory following intra-articular hyaluronic acid injection in knee osteoarthritis--meta-analysis. Osteoarthritis Cartilage 19: 611-619. 